\title{
Game Insight Skills as a Predictor of Talent for Youth Soccer Players
}

\author{
Tom de Joode ${ }^{1 *}$, Drewes J. J. Tebbes ${ }^{1}$ and Geert J. P. Savelsbergh ${ }^{1,2,3 *}$ \\ ${ }^{1}$ Department of Human Movement Sciences, Vrije Universiteit Amsterdam, Amsterdam Movement Sciences, Amsterdam, \\ Netherlands, ${ }^{2}$ Institute of Brain and Behavior, Amsterdam, Netherlands, ${ }^{3}$ Faculty of Sports and Nutrition, Amsterdam \\ University of Applied Sciences, Amsterdam, Netherlands
}

\section{OPEN ACCESS}

Edited by:

Alberto Lorenzo Calvo,

Universidad Politécnica de

Madrid, Spain

Reviewed by:

Daniel Castillo,

Universidad Isabel I de Castilla, Spain Bruno Travassos,

University of Beira Interior, Portugal

${ }^{*}$ Correspondence:

Tom de Joode

t.de.joode@vu.n

Geert J. P. Savelsbergh

g.j.p.savelsbergh@vu.nl

Specialty section: This article was submitted to Elite Sports and Performance

Enhancement,

a section of the journal

Frontiers in Sports and Active Living

Received: 22 September 2020

Accepted: 30 November 2020

Published: 15 January 2021

Citation:

de Joode T, Tebbes DJJ and Savelsbergh GJP (2021) Game Insight Skills as a Predictor of Talent for Youth

Soccer Players.

Front. Sports Act. Living 2:609112. doi: 10.3389/fspor.2020.609112
Perceptual-cognitive skills are found to be important factors for soccer players. The aim of this study was, therefore, to find within-group differences for game insight in an elite group of youth soccer players by means of a Game Insight inDicator (GID). In addition, the prospective value of perceptual-cognitive skills was examined by following the trajectory of the participants. The GID consisted of film clips that show game situations. The task of the players was to predict the trajectory and destination of the ball and move toward the correct position to receive the pass of a teammate. The film clips stopped $80 \mathrm{~ms}$ before, at, and $80 \mathrm{~ms}$ after the football contact of a teammate. We also sought to validate the GID against game performance. Participants were talented soccer players 11-13 years old and playing at the elite level for their age. Based on eight independent elite-coach judgments, two groups were created: highly talented players $(H T)$ and less talented players (LT). The coach ratings were supported by a significant difference between the two groups based on the objective notational analysis of their game performance in 4 vs. 4 and 11 vs. 11 matches. With respect to the GID, a significant interaction effect for the groups (HT vs. LT) by occlusion time $(-80,0$, and $+80 \mathrm{~ms})$ was found, showing that the HT performs better than the LT in 0 and +80 ms condition. In addition, GID scores were compared with soccer levels at the mean age of 19 years. Longitudinal data did not show significant differences between elite and sub-elite. Overall, the GID was found to be a valid and useful indicator for players anticipating the ball's trajectory and destination at age 11-13 years but failed to predict the players' level at age 19 years. The latter indicates how difficult it is to predict talent development.

Keywords: perceptual-cognitive skills, game insight indicator, talent identification, youth elite soccer players, occlusion task, anticipation, decision making

\section{INTRODUCTION}

Most ball sports require the ability to intercept or pass the ball. To succeed, one has to be capable of anticipating the ball's trajectory and destination. When visual information available for players is limited, they have to rely even more on their capability to extract relevant cues from the limited amount of visual information available. This skilled perception is found to be a valid differentiator between expert and less-expert players. Major findings from several studies have shown that expert athletes can extract more relevant information from pre-ball flight cues than their less-expert counterparts (Mann et al., 2007; Savelsbergh et al., 2010). Thereby occlusion of sport-specific video, occluded at or near-final ball contact, can differentiate between expert and less-expert soccer players when the players are asked to follow the direction of the ball in the video (Savelsbergh et al., 2002). 
The research paradigm using the temporal occlusion of visual information was first introduced by Abernethy and Russell (1987) in squash to investigate the level of anticipation between expert and non-expert players. Later studies have reported that the discrepancy of anticipation capacity between expert and nonexpert players also holds in many other ball sports such as tennis, baseball, cricket, and soccer (Houlston and Lowes, 1993; French et al., 1995; McPherson, 2000; Savelsbergh et al., 2002).

Perceptual-cognitive skills are reported to be crucial factors for soccer players (Roca et al., 2012). Furthermore, the literature on the occlusion paradigm suggests that perceptual-cognitive skills might be highly relevant for talent identification (TID). TID aims to recognize players in sports who will be successful in the future (Williams and Reilly, 2000). Literature has shown that this "talent" is something that does not remain stable and evolves with experience or expertise (Abbott and Collins, 2004; Vaeyens et al., 2008). Consequentially, the use of physiological measures such as height or sprint speed for TID might be affected by improper judgment. These improper judgments are developed by pitfalls in TID, such as the relative age effect and selection biases (Vaeyens et al., 2008; Christensen, 2009). Shifting toward psychological predictors of talent relatively less affected by latter pitfalls is more promising (Mann et al., 2017; Murr et al., 2018). For instance, as players increase with age, the general standard of skills and technical ability keeps getting better. This would mean that the technical skills of the successful players who reach the top would be extremely high, and the distinguishing factor of experts and novices on that level might not be in technical expertise but expertise in the mental aspect of the game (Woods et al., 2016a).

Perceptual-cognitive skills are typically measured with verbal or notational measures (Abernethy and Russell, 1987; Savelsbergh et al., 2002; Kannekens et al., 2009; Woods et al., 2016b). Earlier research found, for instance, that soccer players who scored high on the Tactical Skills Inventory for Sports positioning and deciding scale (procedural knowledge) had more chance to reach professional soccer than players who scored low on those scales (Kannekens et al., 2011). In another study, participants watched an occlusion video clip regarding a certain game situation and responded accordingly by circling a decision on a paper. The study consisted of 25 talented and 25 nontalented Australian football players, and the results showed that the talented participants made more accurate decisions (Woods et al., 2016b). These results should be highly relevant for TID in soccer. However, it was found that self or verbal reports measure individual processes, whereas tactical behavior is based upon the interaction between an organism and the environment (Araújo et al., 2010). According to the ecological approach, perception and action continuously interact (Gibson, 1979). Moreover, an athlete during a match, training, or when tested will continuously adapt to the environment and make decisions accordingly. In that regard, the process of identifying talented athletes should take into account an environment in which perception and action are related (Araújo et al., 2009).

In an attempt to create a setting in which perceptual-cognitive skills are measured in a "natural" setting, the Game Insight inDicator (GID) was developed (Savelsbergh et al., 2006, 2010). During the GID, participants react to a positional soccer game shown on a screen in front of the participant. The positional game is occluded before a pass is given toward the participant. The participants move as fast as possible to the position they perceive to intercept the ball after the video was occluded. Savelsbergh et al. (2010) found that skilled amateur youth soccer players were more accurate in moving toward the correct position to intercept the ball than the less skilled players (Savelsbergh et al., 2010). However, the validity of video-based decision making is questioned (Bennett et al., 2019). The latter study underlined the use of sport-specific response actions and a realistic view without removing key contextual information for decision making in a test setting. In addition, the study concluded that within-group differences should be found with a TID tool for practical relevancy.

With current knowledge regarding TID and video assessment tools, the GID should be further examined for practical relevance. Validation of GID could be improved, as no research has examined the GID in relation to in situ game insight and game performance. Furthermore, coaches' judgment in regard to perceptual-cognitive skills should be further examined, as it can be highly relevant for TID to know whether coaches can differentiate better and lesser perceptual-cognitive players. In addition, a within-group analysis rather than a betweengroup analysis should be conducted, as it might reveal more detailed information for successful performance determinants and practical use (Savelsbergh et al., 2005; Bennett et al., 2019). Additionally, the GID was proposed as a TID indicator; nevertheless, no study has been conducted to examine the prospective value of the GID. Therefore, the current experiment expands that of Savelsbergh et al. (2010) by adding four elements: (1) Independent coaches ranked players according to their game insight abilities during a 4 -vs.-4 small-sided game (SSG); (2) participants were ranked in both 4 -vs. -4 and 11 -vs.-11 games using an objective rating system; (3) all participants were elite rather than skilled amateur youth soccer players, all playing at a Dutch elite soccer club; and (4) current soccer level was compared with GID data.

This study frame is different from previous literature, as it examines elite players in their youth and at the expertise level. To our knowledge, this is the first study that examines the prospective value of perceptual-cognitive skills-measured with an interactive video assessment tool-while also taking the judgment of coaches into account. Thereby, the aim of the present study is 2-fold: (1) to establish within-group differences for game insight in elite youth soccer players; thereby, validation of the GID could be improved by examining both subjective as objective perceptual-cognitive skills; (2) prospective value of perceptual-cognitive skills is examined by following the trajectory of the participants.

According to previous literature, expert athletes can extract more relevant information than less-expert athletes (Mann et al., 2007; Savelsbergh et al., 2010). Research also showed that early recognition of visual information could lead to better anticipation on the part of experts during given situations (Abernethy and Russell, 1987; Helsen and Starkes, 1999; Williams and Elliott, 1999; Savelsbergh et al., 2002, 2005; Vaeyens et al., 2007). Therefore, it is hypothesized that the GID can differentiate 
between talented and less-talented players, even within a highly homogenous elite group and at a later age.

\section{MATERIALS AND METHODS}

\section{Participants}

Fourteen youth soccer players playing in the U12 or U13 team (mean age 12.2 years, $\mathrm{SD}=0.5$ ) for an elite youth academy in the Netherlands participated in the study. The self-reported mean age, height, and body weight were, respectively, 12.2 years $(\mathrm{SD}=0.13), 149 \mathrm{~cm}(\mathrm{SD}=2.0)$, and $37.8 \mathrm{~kg}(\mathrm{SD}=1.5)$. Their self-reported soccer experience was 6.8 years $(S D=1.0)$ and experience at an elite youth academy $(\mathrm{M}=3.6$ years, $\mathrm{SD}=$ 2.3). Coaches associated with the club but independent from the players were asked to watch and rank the players for game insight. This minimized the prior knowledge the coaches had about the players. All coaches were qualified trainers working with elite level players. Before the research, trainers and club management received an explanation of the measurements, the risks, and the benefits of the study. Parents or guardians were asked to sign an informed consent before the measurements. The study was conducted in agreement with the local university's ethics committee.

\section{Materials}

Video cameras recorded the clips for the GID, the regular games, and the SSGs. Video footage was projected on a 2.4 by $2.4 \mathrm{~m}$ screen with a video projector (Benq MX 717). An artificial turf mat was placed on the floor in front of the screen, enabling the players to wear their regular soccer shoes. The participant's positions were recorded using a Microsoft Xbox 360 Kinect sensor with coordinates saved on a laptop (HP EliteBook 8570W). The Kinect has been validated for large body movements (Geerse et al., 2015). All measurements were performed in one of the change rooms within the club's facilities (Figure 1).

\section{Game Insight inDicator Clips}

GID footages were recordings of a position game played on an 18.3 by $18.3 \mathrm{~m}$ field by 4 -vs. -4 peer-aged players with additional two wildcard players. Both wildcard players were lined up on opposite sidelines, returning the ball to the team originally playing the ball. This created a 6 vs. 4 advantage for the team in ball possession. Four games of $5 \mathrm{~min}$ each were recorded by two cameras positioned on a wildcard's sideline (see Figure A1). Video clips were eligible for the GID if the ball was played in the general direction of one of the cameras, without any obstruction by a player. Based on previous research, three different occlusion types were specified (Abernethy and Russell, 1987; Savelsbergh et al., 2006):

- Clip occludes $80 \mathrm{~ms}$ before football contact (-80 ms) (screen turns black)

- Clip occludes at football contact (0 ms) (screen turns black)

- Clip occludes $80 \mathrm{~ms}$ after football contact (+80 ms) (screen turns black)

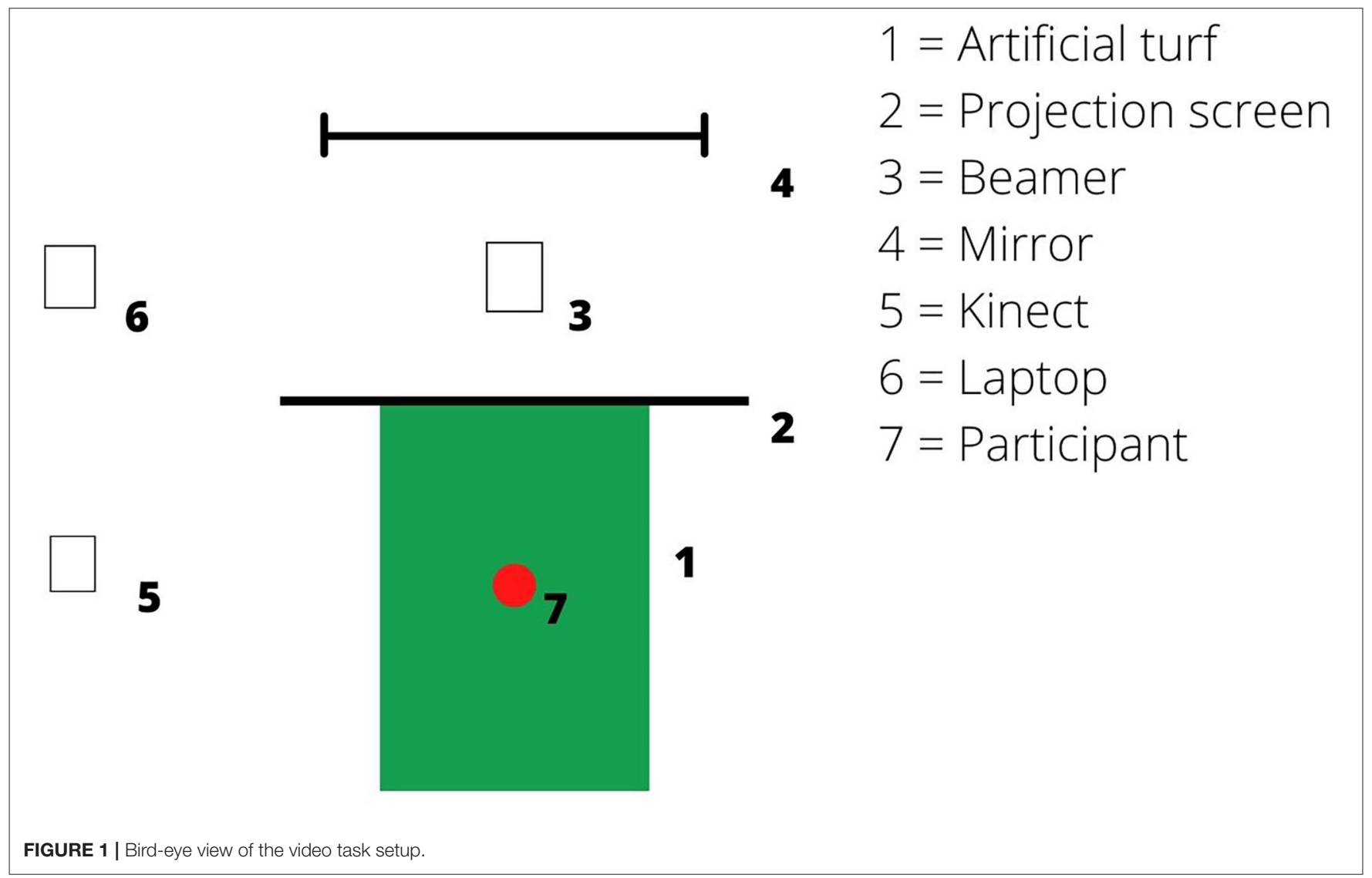




\section{Questionnaire}

Participants self-reported anthropometrics (height and weight), soccer experience (at the current and previous clubs), time participating in other sports, and time spent playing outdoors. The questionnaire consisted of the following questions:

- Date of birth?

- What are your height and weight?

- Which position do you play? (goalie, defender, midfielder, or forward)

- How many years have you played soccer in general?

- How many years of those have you played at this club?

- How many hours a week do you practice for soccer?

- How many hours a week do you spend playing outdoors?

\section{Procedure}

\section{Rating Game Insight Abilities}

Participants were involved in five 6-min SSGs with 2-min breaks between the games. SSGs are shown to replicate situations and skill requirements of regular match play (Owen et al., 2004; Rampinini et al., 2007). Thereby, varying the pitch size or amount of players can provide different training responses for physical, physiological, or perceptual loads. For instance, reducing the number of players results in a significant increase of ball contacts and tactical decisions performed by a single player (Owen et al., 2004; Jones and Drust, 2007; Duarte et al., 2009). There is, however, a lack of consistent use of SSG design (Hill-Haas et al., 2011). The current study uses the SSG design 4 -vs.-4 with five 6 min SSGs and 2 min breaks in between, as it was part of the training to increase physiological demands. This 3:1 work/rest ratio is within the range of previous research regarding SSG (HillHaas et al., 2011). All teams consisted of four players, and the composition of the teams was shuffled every game to prevent social preference bias. The field measurements were 20 by $40 \mathrm{~m}$ with a small goal placed on either side. Compared with previous literature, this pitch size was relatively long for an SSG (HillHaas et al., 2011). This caused increased physiological demands without affecting the technical demands (Owen et al., 2004). In addition, this longer and narrow pitch was assumed to increase longitudinal inter-team distance and decrease lateral inter-team distance (Frencken et al., 2013). Therefore, it was assumed that there would be more longitudinal space and, thereby, more situations to play the ball forward or backward. These in situ situations were examined with the GID videos.

For both the U12 and U13 teams, four independent coaches viewed the video of the five SSGs and separately ranked the players. In total, eight coaches ranked the players according to their game insight abilities. The definition used for game insight is "to act appropriately with the given situation." Coaches gave participants a score on a scale from one to three, one for performing best and three for performing worst. All coaches judged every player in their allocated age group at least twice, with a maximum of four times. All participants were ranked 10 times. The participants rated a " 1 " $70 \%$ or more were placed in the highly talented group. The participants rated a " 1 " $30 \%$ or less were placed in the less talented group. This rating was used as the gold standard of game insight in this study. Accordingly, the performance of participants on the GID and for other variables was analyzed when comparing the highly and less talented group.

\section{Video Occlusion Task}

The GID consisted of 60 occlusion clips, proportionally distributed for three occlusion conditions (Côté et al., 2003). The first three trials were disregarded to allow the participants to familiarize themselves with the setup. The task required participants to anticipate the trajectory of the oncoming ball when visual information was occluded. Before the task, the participants received a brief explanation about the experimental setup and instructions regarding the GID. The task was to be considered a (real-)life-size video game instead of a scientific experiment. In each trial, the ball was played toward the participant or to their left or right. The participants were instructed to receive or intercept the ball, which could be achieved through lateral movements in front of the screen. Before each trial, participants were instructed to return to the center of the screen to prepare for the next trial. When the video clip ended, the participants' positions were recorded with the Kinect for an additional $3 \mathrm{~s}$ to capture any movement after occlusion. No feedback was given about performance, but continuous supportive comments were made to aid the participant in maintaining their focus. The occlusion score was determined by calculating the percentage of correct responses to receive or intercept the ball. For each condition (19 trials per condition), the maximum score was $33 \%$. So, for instance, at one condition, 12 correct responses correspond with $21 \%$.

\section{Game Performance}

Game performance was analyzed during SSGs and regular games. The same footage in which the coaches viewed and ranked the players for game insight was used for analyzing the game performance. Footage of regular competition games was acquired during regular games, which were held in accordance with the Royal Dutch Soccer Association rules on a 60 by $100 \mathrm{~m}$ field. The first 30 min of each half was analyzed independently by two notation analysts. Any additional time was excluded from the analysis. Table 1 consists of all variables and the definitions for which the players were rated. The mean percentage of the sum of successful actions was used as an indicator for game performance. Whether the pass, pass reception, or interception was successful depended on the outcome. An action was deemed successful if the team remained in possession or regained possession from the opponent.

\section{Dependent Variables, Data Analysis, and Statistics}

To conduct analyses for the GID, all x,y,z-coordinates and frame numbers were extracted from the Kinect data. The starting position was determined by determining the participants' mean position over the first 50 frames. Participants' position at the moment of occlusion was used as the final position. A movement of more than $15 \mathrm{~cm}$ from the relative starting position was arbitrarily chosen to differentiate among a left, right, or middle response. The dependent variable for GID was the percentage of correct responses. The dependent variable 
for the SSG and competition game was the mean percentage of the sum of successful first touches, passes, forward passes, and interceptions.

TABLE 1 | Definition of parameters used for the rating of game performance.

\begin{tabular}{|c|c|}
\hline Parameter & Definition \\
\hline Receive & $\begin{array}{l}\text { Player gains or attempts to gain control of the ball to } \\
\text { retain possession }\end{array}$ \\
\hline Well-received & $\begin{array}{l}\text { The player successfully gains or attempts to gain control } \\
\text { of the ball to retain possession }\end{array}$ \\
\hline $\begin{array}{l}\text { Defensive } \\
\text { pressure/interception }\end{array}$ & $\begin{array}{l}\text { Preventing an opponent's pass from reaching its } \\
\text { intended destination or put pressure on a player in } \\
\text { possession of the opponent }\end{array}$ \\
\hline $\begin{array}{l}\text { Successful } \\
\text { defensive } \\
\text { pressure/interception }\end{array}$ & $\begin{array}{l}\text { Successfully preventing an opponent's pass from } \\
\text { reaching its intended destination or put successfully } \\
\text { pressure on a player in possession of the opponent }\end{array}$ \\
\hline Number of passes & $\begin{array}{l}\text { Pass: Player in possession sends the ball to a teammate } \\
\text { (e.g., using the foot, thigh, or chest; using various } \\
\text { techniques such as ground, lofted, chip, flick, or volley; } \\
\text { over short or long distances) }\end{array}$ \\
\hline $\begin{array}{l}\text { Number of passes } \\
\text { correct }\end{array}$ & $\begin{array}{l}\text { Amount of successful passes given by a player in a } \\
\text { match }\end{array}$ \\
\hline $\begin{array}{l}\text { Number of passes } \\
\text { forward }\end{array}$ & Amount of passes forward given by a player in a match \\
\hline $\begin{array}{l}\text { Number of passes } \\
\text { forward correct }\end{array}$ & $\begin{array}{l}\text { Amount of successful passes forward given by a player } \\
\text { in a match }\end{array}$ \\
\hline
\end{tabular}

Statistical analyses were performed with SPSS (IBM SPSS Statistics 26.0). An independent $t$-test was used to compare the highly and less talented groups for rating by coaches, rating game performances, and the questionnaire. A mixed analysis of variance design, with between-subject factor groups, was performed to evaluate coach rating for the group [highly talented (HT) vs. less talented (LT)] and occlusion time ( -80 vs. 0 vs. +80$)$. If Mauchly's test was not significant $(p>0.05)$, the sphericity assumption was accepted; if not, a GreenhouseGeisser correction was used. Post hoc pairwise comparisons were done with independent $t$-tests to examine if there was a significant interaction effect.

\section{RESULTS}

\section{Coach Rating}

Based on the mean coach ratings, HT and LT participant groups were created. The HT group consisted of five players rated a " 1 " $70 \%$ or more $(N=5)$. The LT group consisted of eight players who were rated a " 1 " $30 \%$ or less. This excluded one player from further analysis. The overview per coach and player is found in Table 2.

A significant difference $(p<0.001)$ was found for the ratings of the players across the HT group $(\mathrm{M}=1.2, \mathrm{SD}=0.16)$ and LT group $(\mathrm{M}=2.25, \mathrm{SD}=0.52)$ (Table 3$)$. Also, significant differences were detected in the game performance for both the $4 \mathrm{v} 4$ and the $11 \mathrm{v} 11$ games between the HT group $(\mathrm{M}=85.84, \mathrm{SD}$

TABLE 2 | (A) Overview coach ratings U12 players. (B) Overview of coach ratings U13 players.

\begin{tabular}{|c|c|c|c|c|c|c|c|c|c|c|c|c|c|c|c|c|c|c|c|c|c|}
\hline \multirow[b]{2}{*}{$\begin{array}{l}\text { Players } \\
\text { U12 }\end{array}$} & \multicolumn{5}{|c|}{ Trainer 1} & \multicolumn{5}{|c|}{ Trainer 2} & \multicolumn{5}{|c|}{ Trainer 3} & \multicolumn{5}{|c|}{ Trainer 4} & \multirow{2}{*}{ "1"\% } \\
\hline & L1 & L2 & L3 & L4 & L5 & L1 & L2 & L3 & L4 & L5 & R1 & $\mathbf{R} 2$ & R3 & R4 & R5 & R1 & $\mathbf{R} 2$ & R3 & R4 & R5 & \\
\hline
\end{tabular}

\begin{tabular}{|c|c|c|c|c|c|c|c|c|c|c|c|c|c|c|c|c|c|c|c|c|c|c|}
\hline \multicolumn{23}{|l|}{ A } \\
\hline$A$ & 2 & & & & & 2 & & & & & & 3 & 3 & 3 & 3 & & 3 & 3 & 3 & 3 & 2,8 & 0 \\
\hline B & 3 & & 3 & 3 & 3 & 3 & & 3 & 3 & 3 & & 3 & & & & & 3 & & & & 3 & 0 \\
\hline C & & & & 3 & & & & & 2 & & 1 & 2 & 1 & & 3 & 2 & 2 & 2 & & 1 & 1.9 & 30 \\
\hline $\mathrm{D}$ & & 2 & 1 & & 1 & & 2 & 1 & & 1 & 3 & & & 1 & & 1 & & & 1 & & 1,5 & 70 \\
\hline$E$ & & 3 & & 3 & 3 & & 3 & & 2 & 3 & 2 & & 2 & & & 3 & & 1 & & & 2,5 & 10 \\
\hline $\mathrm{F}$ & 1 & & & & & 1 & & & & & & 2 & 1 & 1 & 1 & & 1 & 1 & 1 & 1 & 1,1 & 90 \\
\hline$G$ & 1 & & 1 & 1 & 1 & 1 & & 1 & 1 & 1 & & 1 & & & & & 1 & & & & 1 & 100 \\
\hline \multirow[t]{2}{*}{$\mathrm{H}$} & 2 & 2 & & & & 2 & 2 & & & & & & 2 & 2 & 1 & & & 2 & 2 & 2 & 1,9 & 10 \\
\hline & \multicolumn{5}{|c|}{ Trainer 5} & \multicolumn{5}{|c|}{ Trainer 6} & \multicolumn{5}{|c|}{ Trainer 7} & \multicolumn{5}{|c|}{ Trainer 8} & & "1"\% \\
\hline $\begin{array}{l}\text { Players } \\
\text { U13 }\end{array}$ & L1 & L2 & L3 & L4 & L5 & L1 & L2 & L3 & L4 & L5 & R1 & R2 & R3 & R4 & R5 & R1 & $\mathbf{R} 2$ & R3 & R4 & R5 & Mean & \\
\hline
\end{tabular}

\begin{tabular}{|c|c|c|c|c|c|c|c|c|c|c|c|c|c|c|c|c|c|c|c|c|c|c|}
\hline \multicolumn{23}{|l|}{ B } \\
\hline I & & 1 & & & 1 & & 2 & & & 2 & 2 & & 3 & 3 & & 2 & & 3 & 3 & & 2,2 & 20 \\
\hline J & & 1 & 1 & 2 & & & 3 & 1 & 1 & & 1 & & & & 1 & 2 & & & & 1 & 1,4 & 70 \\
\hline K & 3 & 3 & 2 & & 2 & 3 & 3 & 2 & & 1 & & & 2 & & & & & 2 & & & 2,3 & 10 \\
\hline L & & & 1 & 1 & 1 & & & 1 & 1 & 1 & 1 & 2 & & & & 1 & 2 & & & & 1,2 & 80 \\
\hline $\mathrm{M}$ & 1 & 2 & & & & 2 & 2 & & & & & & 1 & 1 & 1 & & & 1 & 1 & 1 & 1,3 & 70 \\
\hline $\mathrm{N}$ & 1 & & & 1 & & 2 & & & 2 & & & 1 & 1 & & 2 & & 1 & 1 & & 2 & 1,4 & 60 \\
\hline
\end{tabular}


TABLE 3 | Relevant variables between HT and LT group, "significant $(p<0.05)$.

\begin{tabular}{|c|c|c|c|}
\hline Variable & $\begin{array}{c}\text { HT Group }(N=5) \\
\text { Mean (SD) }\end{array}$ & $\begin{array}{l}\text { LT Group }(N=8) \\
\text { Mean (SD) }\end{array}$ & $T$-value $(p)$ \\
\hline $\begin{array}{l}\text { Rating by the } \\
\text { coaches }\end{array}$ & $1.2(0.16)$ & $2.25(0.52)$ & $4.3(<0.000)^{\star}$ \\
\hline $\begin{array}{l}\text { Game } \\
\text { performance in } \\
4 \mathrm{v} 4\end{array}$ & $85.84(8.2)$ & 69.7 (5.8) & $-4.2(<0.001)^{\star}$ \\
\hline $\begin{array}{l}\text { Game } \\
\text { performance in } \\
11 \mathrm{v} 11\end{array}$ & $86.82(6.8)$ & 63.26 (9.3) & $-4.9(<0.005)^{\star}$ \\
\hline $\begin{array}{l}\text { Hours spent } \\
\text { playing outdoors }\end{array}$ & $10.2(2.8)$ & $7.3(3.8)$ & $-1.5(0.152)$ \\
\hline
\end{tabular}

$=8.2 ; \mathrm{M}=86.82, \mathrm{SD}=6.8)$ and the $\mathrm{LT}$ group $(\mathrm{M}=69.7, \mathrm{SD}=$ $5.8 ; \mathrm{M}=63.26, \mathrm{SD}=9.3$ ).

The group $(\mathrm{HT}$ vs. LT) $\times$ Occlusion $(-80$ vs. 0 vs. +80$)$ testing was carried out. The sphericity assumption was accepted due to non-significant Mauchly's test $(p>0.05)$. For the main factor of the group, no significant effect was found $F_{(2,11)}=2.8$, $p=0.106$. The main effect of occlusion was significant $F_{(2,22)}$ $=5, p=0.016, \eta_{p}^{2}=0.313$, whereas the analysis revealed a significant interaction between group and occlusion $F_{(4,22)}=$ 3.4, $p=0.025, \eta_{p}^{2}=0.385$ (Figure 2A). An independent $t$-test for GID score showed a significant difference, $t(11)=-3.2, p$ $=0.009$, between score on 0 -ms clips for talented $(\mathrm{M}=19$, $\mathrm{SD}=6.4)$ and less talented group $(\mathrm{M}=9, \mathrm{SD}=5)$. Also, a significant difference, $t(11)=-2.3, p=0.04$, was found between score on +80 -ms clips for talented $(\mathrm{M}=21, \mathrm{SD}=6)$ and less talented group $(\mathrm{M}=12, \mathrm{SD}=7)$. For total occlusion score, there was also a significant effect $(p<0.05)$ found for HT group $(\mathrm{M}=48.2 \mathrm{SD}=12.6)$ compared with the LT group $(\mathrm{M}=28.4, \mathrm{SD}=13.6)$.

\section{Seven Years Later}

Seven years after the original measures, 9 of the 14 players still played soccer at a high level (i.e., in the first league for their age). The playing levels of the participants (mean age of 19 years) are reported in Table 4.

Three out of the six original HT players were playing at the highest level (1), one was performing at the thirdbest level (3), one at the fourth-best level (4), and one player, unfortunately, had to quit soccer due to reasons other than his soccer skills and was therefore excluded for further analysis. Five of the seven players-originally classified as LT players by the coaches-also played at the highest level. Additional analysis found no significant effect on the main factor group $(p=0.568)$ between sub-elite and elite players (Figure 2B). Also, no significant effect was found for interaction effect between group and occlusion $(p=0.634)$ between the elite $(N=9)$ compared with sub-elite $(N=4)$.

\section{DISCUSSION}

The purpose of this study was to verify and expand findings by Savelsbergh et al. and improve the validation of the GID. In previous research, the GID was validated as a differentiator between skilled amateur youth players (Savelsbergh et al., 2010). However, the capabilities of video-based decision-making have been questioned (Bennett et al., 2019). The current findings confirm our hypothesis that talented and less-talented youth participants can be identified on the basis of their performance on the occlusion task. Within a highly homogenous elite group, the HT group outperforms the LT group for occlusion task and game performance (Table 3, Figure 2A). This also indicates that independent elite coaches can differentiate HT players and LT players within only $30 \mathrm{~min}$ of SSG play. Further, these coach ratings are supported by the significant difference between the two groups revealed by objective notational analyses of the 4-vs.4 and 11-vs.-11 game performance.

A significant interaction effect for occlusion and group was found. A clear difference was observed visually between the HT and LT groups (Figure 2A). This is in line with earlier literature stating that expert athletes can extract more relevant information than less-expert athletes (Mann et al., 2007; Savelsbergh et al., 2010; Roca et al., 2012). In the current study, the -80 and +80 ms occlusion scenarios do not (quite) differentiate between the HT and LT groups. From the literature, it is well-known that adult experts are capable of extracting relevant cues at $160 \mathrm{~ms}$ before final ball contact and that $-80 \mathrm{~ms}$ occlusion trials show to be a good occlusion scenario to discriminate within expert adults (Abernethy, 1990; Mann et al., 2007). The current study showed that the $-80 \mathrm{~ms}$ occlusion trials were too difficult for the young participants. Explanations that may account for this: (1) the cognitive functioning of the young brain has not been fully developed and lacks the processing speed; (2) the participants do not have the amount of experience of adults and lack a reference framework to compare the current situation with; (3) It may yet not be necessary for youth players to make anticipation for that time constraint (Weissensteiner et al., 2008). In addition, it has been suggested that children need more time to decide during an occlusion task (Savelsbergh et al., 2010). The +80 and $0 \mathrm{~ms}$ occlusion scenarios seem to be good methods to discriminate within a highly talented youth soccer group between HT and LT players. The uptrend in Figure 2A for LT players at $+80 \mathrm{~ms}$ trials reflects the elite level of the participants. Future research should indicate whether $+80 \mathrm{~ms}$ scenarios discriminate more between sub-elite and elite.

By using both subjective and objective measurements, the current study presents a broad view of game insight. Elite coaches created both the HT and LT groups on their game insight abilities. Between both groups, a significant difference in game performance, measured by objective analysis, was observed. Current findings, therefore, note the importance of game insight during a game performance, whereas game performance depends on multidisciplinary skills (Larkin and O'Connor, 2017). GID might, therefore, be an important tool to indicate game insight and game performance. Nevertheless, there might be a 
A

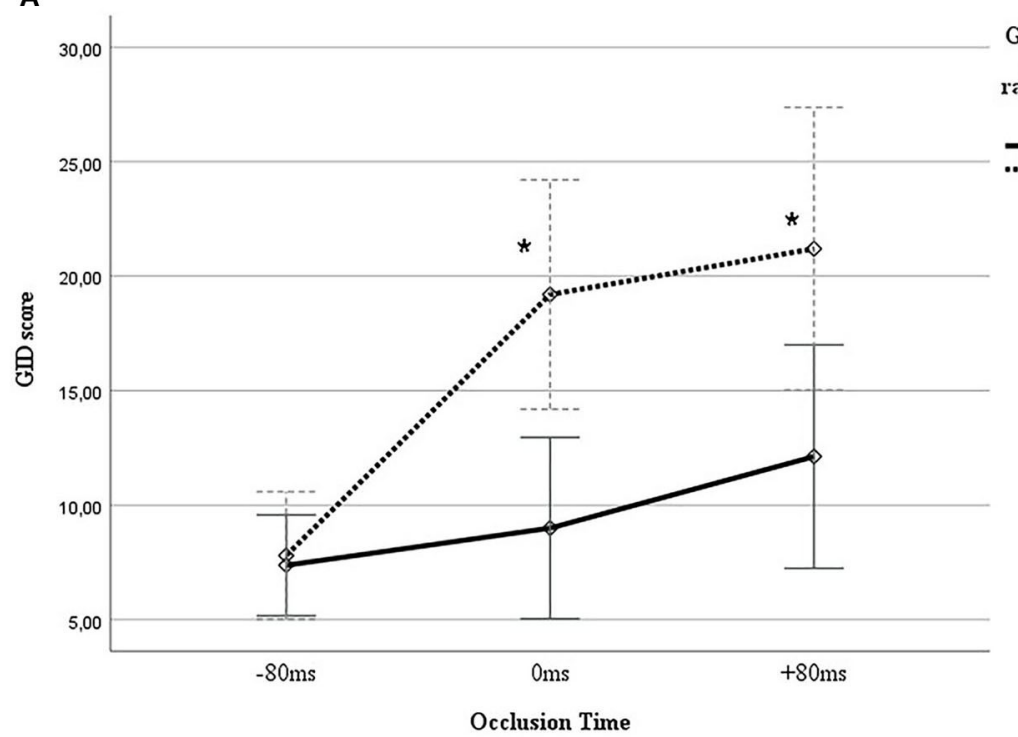

Grouping based

on coaches'

rating amount of

' 1 '

- Less Talented

.... High Talented

B

Error bars: +/- $2 \mathrm{SE}$

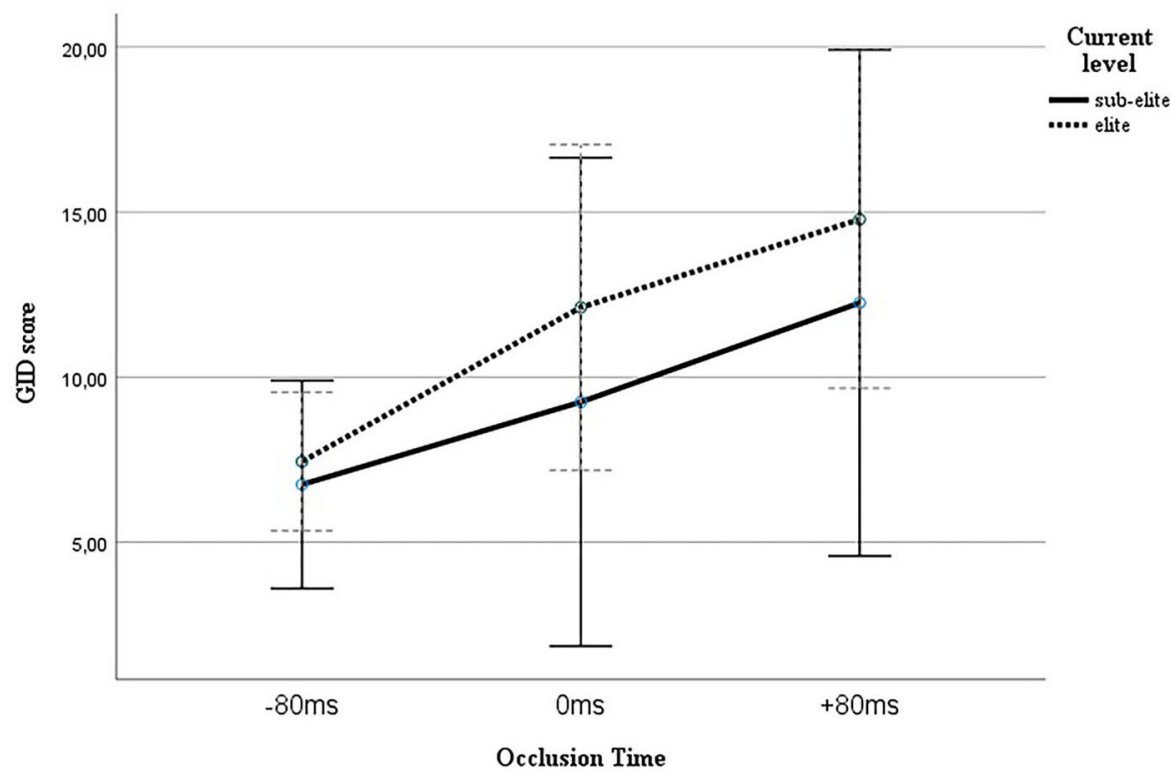

Error bars: +/- $2 \mathrm{SE}$

FIGURE 2 | (A) Interaction effect for the Group *Occlusion for groups based on coaches rating. *Significant $(p<0.05)$. (B) Interaction effect for the Group * Occlusion for groups based on current level.

discrepancy between the GID and real gameplay. Game insight during gameplay is suggested to be characterized by explorative behavior, which increases the rate of successful actions of soccer players (Jordet et al., 2013; McGuckian et al., 2018). A recent study, thereby, proposes that players who have knowledge regarding their surroundings can make better actions accordingly (McGuckian et al., 2018). GID measures perceptual-cognitive skills in the frontal plane and, therefore, might require less explorative behavior than the in situ gameplay, which requires a three-dimensional view (Vaeyens et al., 2008). The latter suggests that the GID is less representative of real gameplay and, therefore, might not be suitable for TID regarding perceptual-cognitive skills (Shim et al., 2005; Bennett et al., 2019). However, identifying talent should be executed in an environment with an intact coupling between perception and action (Araújo et al., 2009). In addition, the task should be representative of soccer matches and require the execution of sport-specific skills (Travassos et al., 2013; Bennett et al., 2019). During the GID, participants are 
TABLE 4 | Current soccer level 2019/2020.

\begin{tabular}{llc}
\hline Participant & Group & Current soccer level \\
\hline F & HT & 1 \\
L & HT & 3 \\
M & HT & 1 \\
G & HT & Quit \\
D & HT & 4 \\
J & HT & 1 \\
A & LT & 3 \\
B & LT & 1 \\
C & LT & 1 \\
E & LT & 1 \\
H & LT & 5 \\
I & LT & 1 \\
K & LT & 1 \\
N & MT & 1 \\
& &
\end{tabular}

Playing level 1 is the highest possible level-still playing in a premier club at the highest division - whereas level 5 is playing in the fourth division.

tasked to receive the ball and not give a pass afterward or make a certain action. Therefore, the GID creates a decision-making situation that is encountered by players during regular games. In addition, the GID provides environmental information such as teammates and task requirements, which decision-making tasks should consist of Araújo et al. (2006) and Mann et al. (2007). The GID also contains decision and processing speeds required during a competition, which should be reflected during practice sessions (Farrow and Raab, 2008). Overall, the GID gives a representative view of decision making and might be a more suitable tool to measure tactical decision making than verbal or written tests (Van Der Kamp et al., 2008; Araújo et al., 2009, 2010; Travassos et al., 2013). The latter is supported by the findings that in situ performance of SSGs did not relate to self-reported procedural data (Nortje et al., 2014). This is in line with the idea of Van Der Kamp et al. (2008) that an experimental study regarding decision making should require participants to act rather than to write or communicate. The GID, however, is performed in a controlled laboratory setting. A limitation, therefore, is the presence of a discrepancy of perception-action coupling between in situ and the controlled setting. The perception in a laboratory setting is found to be different, whereas the player in the natural setting has to perform the required action according to the perceived information (Dicks et al., 2010). The intention with the GID is only to move toward a position to intercept the ball without performing the interception. Current results, however, indicate that occlusion scores differentiate for in situ game insight. Nevertheless, further research should be undertaken to compare occlusion scores with explorative behavior during real gameplay to increase the validity of the GID and in situ decision making.

\section{Seven Years Later}

Longitudinal data show that five of the seven players-which were originally classified as LT players by the coaches-played at the highest level at mean age 19 years. This indicates how difficult it is to predict talent development. Current data show that trainers should not base their decision on (de)selecting exclusively on GID score. Nevertheless, although there was no significant difference for longitudinal data, GID is still very promising as the elite group scored better than the less group (Figure 2B). The improvement of the less group might be caused by the nature of the soccer club, i.e., having a long-distance plan with their youth players. During the years of training, the "less talented" players could have increased their perceptual-cognitive, and other skills, with the number of training hours at the elite level. GID could, therefore, be a valuable tool for measuring and evaluating the development of perceptual-cognitive skills. Future research should examine longitudinal data for the GID with a larger sample size to indicate the usefulness of the GID for talent prediction.

\section{Additional Information}

This section contains findings that are outside the scope of this study. Nevertheless, it contains important and useful information for TID and development. A growing body of evidence arises that children and young adolescence are spending more time indoors and becoming more sedentary (Hallal et al., 2012; Tremblay et al., 2014, 2016). A recent study by Anselma et al. (2020) found that the decrease of physical activity results in a decrease of movement speed, flexibility, and trunk, leg power for children of 10-12 years compared with 10 years before. Another recent study with 2,543 children showed that the physical activity of children with mean a mean age of 10 years was 9.06 hours per week $(S D=5.10)$ (Rodriguez-Ayllon et al., 2020). In comparison, the physical activity per week of the soccer players in the current study was considerably higher. With organized sports hours per week and hours playing outside taken into account, the self-reported total physical activity of the talented players was $14.7 \mathrm{~h}$ and, for the lesser counterparts, $11.8 \mathrm{~h}$ per week. The discrepancy with the non-expert peers might result in an ongoing advancement for elite players, whereas a decrease in physical activity decreases characteristics needed for soccer (Anselma et al., 2020). In addition, outdoor play improves responses to new and challenging environments and social skills (Pellegrini and Smith, 1998; Pellegrini et al., 2007). Furthermore, the extra hours of practice could play a significant role in the development of the players (Côté et al., 2003; Memmert et al., 2010). The motor development of future athletes could, therefore, be hindered and as a consequence the gap between expert elites and novices increases. Future research should take the latter into account and examine whether the gap between novices and expert athletes increases as this might be concerning for the overall level of future athletes.

Overall, the current findings indicate that the GID is a useful indicator for anticipating the ball's trajectory and destination at age 11-13. Although no clear relationship with future performance was found, the GID can be a valuable tool to measure and evaluate perceptual-cognitive skills to examine the process of talent development. Yet, in-situ game insight measurement and coaches evaluation had some limitations. Future research should, therefore, evaluate game performance 
by taking explorative behavior into account. Furthermore, the current findings point to the need to consider the subjective opinions of expert coaches for talent identification. This is in line with recent literature that the judgment of coaches regarding soccer skill rating discriminates between different skill groups (Hendry et al., 2018). Although there is a growing body of literature regarding objective talent predictors, coach judgments are still important and should not be neglected in the selection and deselection of soccer players (Höner and Votteler, 2016). Nevertheless, coaches' evaluations of game insight might be biased. Therefore, it is suggested that future research should implement the actuarial judgment of coaches to improve the evaluation of game insight performance in situ. The actuarial judgment gives more rules for the judgment and decreases the chance of biased judgments (Christensen, 2009; Den Hartigh et al., 2018). Combining both actuarial judgments and the GID could provide a broader understanding of the game insight of soccer players.

\section{DATA AVAILABILITY STATEMENT}

The raw data supporting the conclusions of this article will be made available by the authors, without undue reservation.

\section{REFERENCES}

Abbott, A., and Collins, D. (2004). Eliminating the dichotomy between theory and practice in talent identification and development: considering the role of psychology. J. Sports Sci. 22, 395-408. doi: 10.1080/02640410410001675324

Abernethy, B. (1990). Anticipation in squash: differences in advance cue utilization between expert and novice players. J. Sports Sci. 8, 17-34. doi: 10.1080/02640419008732128

Abernethy, B., and Russell, D. G. (1987). Expert-novice differences in an applied selective attention task. J. Sport Psychol. 9, 326-345. doi: 10.1123/jsp.9.4.326

Anselma, M., Collard, D. C. M., van Berkum, A., Twisk, J. W. R., Chinapaw, M. J. M., and Altenburg, T. M. (2020). Trends in neuromotor fitness in 10-to-12-year-old dutch children: a comparison between 2006 and 2015/2017. Front. Public Health 8:559485. doi: 10.3389/fpubh.2020.559485

Araújo, D., Cordovil, R., Ribeiro, J., Davids, K., and Fernandes, O. (2009). "How does knowledge constrain sport performance? An ecological perspective," in Perspectiveson Sport, eds D. Ara?jo, H. Ripoll, and M. Raab (Hauppauge, NY: Nova Science Publishers), 100-120.

Araújo, D., Davids, K., and Hristovski, R. (2006). The ecological dynamics of decision making in sport. Psychol. Sport Exerc. 7, 653-676. doi: 10.1016/j.psychsport.2006.07.002

Araújo, D., Travassos, B., and Vilar, L. (2010). Tactical skills are not verbal skills: a comment on kannekens and colleagues 1. Percept. Mot. Skills 110, 1086-1088. doi: $10.2466 /$ pms.110.3c.1086-1088

Bennett, K. J. M., Novak, A. R., Pluss, M. A., Coutts, A. J., and Fransen, J. (2019). Assessing the validity of a video-based decision-making assessment for talent identification in youth soccer. J. Sci. Med. Sport 22, 729-734. doi: 10.1016/j.jsams.2018.12.011

Côté, J., Baker, J., and Abernethy, B. (2003). "From play to practice: A developmental framework for the acquisition of expertise in team sport," in Expert Performance in Sports: Advances in Research on Sport Expertise, eds J. Starkes and K. A. Ericsson (Champaign, IL: Human Kinetics), 89-113.

Christensen, M. K. (2009). "An eye for talent": talent Identification and the "Practical Sense" of top-level soccer coaches. Sociol. Sport J. 26, 365-382. doi: $10.1123 /$ ssj.26.3.365

Den Hartigh, R. J. R., Niessen, A. S. M., Frencken, W. G. P., and Meijer, R. R. (2018). Selection procedures in sports: improving predictions

\section{ETHICS STATEMENT}

Ethical review and approval was not required for the study on human participants in accordance with the local legislation and institutional requirements. Written informed consent to participate in this study was provided by the participants' legal guardian/next of kin. Written informed consent was obtained from the minor(s)' legal guardian/next of kin for the publication of any potentially identifiable images or data included in this article.

\section{AUTHOR CONTRIBUTIONS}

GS conceptualized the study. DT and TdJ contributed to the software and data collection. TdJ contributed to the methodology and writing of the original draft. GS reviewed and edited the manuscript and supervised the study. All authors contributed to the article and approved the submitted version.

\section{ACKNOWLEDGMENTS}

The authors want to thank Glenn van der Kraan, the youth coordinator at Feyenoord Academy. of athletes' future performance. Eur. J. Sport Sci. 18, 1191-1198. doi: 10.1080/17461391.2018.1480662

Dicks, M., Button, C., and Davids, K. (2010). Examination of gaze behaviors under in situ and video simulation task constraints reveals differences in information pickup for perception and action. Atten. Percept. Psychophys. 72, 706-720. doi: 10.3758/APP.72.3.706

Duarte, R., Batalha, N., Folgado, H., and Sampaio, J. (2009). Effects of exercise duration and number of players in heart rate responses and technical skills during futsal small-sided games. Open Sports Sci. J. 2, 37-41. doi: 10.2174/1875399X00902010037

Farrow, D., and Raab, M. (2008). "A recipe for expert decision making," in Developing Sport Expertise: Researchers and Coaches Put Theory Into Practice, eds D. Farrow, J. Baker, and C. MacMahon (London: Routledge), 137-154.

French, K. E., Spurgeon, J. H., and Nevett, M. E. (1995). Expert-novice differences in cognitive and skill execution components of youth baseball performance. Res. Q. Exerc. Sport 66, 194-201. doi: 10.1080/02701367.1995.10608833

Frencken, W., Van Der Plaats, J., Visscher, C., and Lemmink, K. (2013). Size matters: Pitch dimensions constrain interactive team behaviour in soccer. J. Syst. Sci. Compl. 26, 85-93. doi: 10.1007/s11424-013-2284-1

Geerse, D. J., Coolen, B. H., and Roerdink, M. (2015). Kinematic validation of a multi-kinect v2 instrumented 10-meter walkway for quantitative gait assessments. PLoS ONE 10:e0139913. doi: 10.1371/journal.pone.0139913

Gibson, J. J. (1979). The Ecological Approach to Visual Perception. Boston, MA: Houghton Mifflin.

Hallal, P. C., Andersen, L. B., Bull, F. C., Guthold, R., Haskell, W., and Ekelund, U. (2012). Global physical activity levels: surveillance progress, pitfalls, and prospects. Lancet 380, 247-257. doi: 10.1016/S0140-6736(12)60646-1

Helsen, W. F., and Starkes, J. L. (1999). A multidimensional approach to skilled perception and performance in sport. Appl. Cogn. Psychol. $13,1-27$.

Hendry, D. T., Williams, A. M., and Hodges, N. J. (2018). Coach ratings of skills and their relations to practice, play and successful transitions from youth-elite to adult-professional status in soccer. J. Sports Sci. 36, 2009-2017. doi: $10.1080 / 02640414.2018 .1432236$

Hill-Haas, S. V., Dawson, B., Impellizzeri, F. M., and Coutts, A. J. (2011). Physiology of small-sided games training in football. Sports Med. 41, 199-220. doi: 10.2165/11539740-000000000-00000 
Höner, O., and Votteler, A. (2016). Prognostic relevance of motor talent predictors in early adolescence: a group- and individual-based evaluation considering different levels of achievement in youth football. J. Sports Sci. 34, 2269-2278. doi: 10.1080/02640414.2016.1177658

Houlston, D. R., and Lowes, R. (1993). Anticipatory cue-utilization processes amongst expert and non-expert wicketkeepers in cricket. Int. J. Sport Psychol. $24,59-73$.

Jones, S., and Drust, B. (2007). Physiological and technical demands of $4 \mathrm{v} 4$ and 8 v 8 games in elite youth soccer players. Kinesiology 39, 150-156.

Jordet, G., Bloomfield, J., and Heijmerikx, J. (2013). "The hidden foundation of field vision in Jordet et al. (2013). Cityenglish premier league (EPL) soccer players," in 7th Annual MIT Sloan Sports Analytics Conference (Boston, MA).

Kannekens, R., Elferink-Gemser, M. T., Post, W. J., and Visscher, C. (2009). Selfassessed tactical skills in elite youth soccer players: a longitudinal study. Percept. Mot. Skills 109, 459-472. doi: 10.2466/pms.109.2.459-472

Kannekens, R., Elferink-Gemser, M. T., and Visscher, C. (2011). Positioning and deciding: key factors for talent development in soccer. Scand. J. Med. Sci. Sports 21, 846-852. doi: 10.1111/j.1600-0838.2010.01104.x

Larkin, P., and O'Connor, D. (2017). Talent identification and recruitment in youth soccer: recruiter's perceptions of the key attributes for player recruitment. PLoS ONE 12:e175716. doi: 10.1371/journal.pone.0175716

Mann, D. L., Dehghansai, N., and Baker, J. (2017). Searching for the elusive gift: advances in talent identification in sport. Curr. Opin. Psychol. 16, 128-133. doi: 10.1016/j.copsyc.2017.04.016

Mann, D. T. Y., Williams, A. M., Ward, P., and Janelle, C. M. (2007). Perceptualcognitive expertise in sport: a meta-analysis. J. Sport Exerc. Psychol. 29, 457-478. doi: 10.1123 /jsep.29.4.457

McGuckian, T. B., Cole, M. H., Jordet, G., Chalkley, D., and Pepping, G.-J. (2018). Don't turn blind! the relationship between exploration before ball possession and on-ball performance in association football. Front. Psychol. 9:2520. doi: 10.3389/fpsyg.2018.02520

McPherson, S. L. (2000). Expert-novice differences in planning strategies during collegiate singles tennis competition. J. Sport Exerc. Psychol. 22, 39-62. doi: 10.1123 /jsep.22.1.39

Memmert, D., Baker, J., and Bertsch, C. (2010). Play and practice in the development of sport? Specific creativity in team ball sports. High Abil. Stud. 21, 3-18. doi: 10.1080/13598139.2010.488083

Murr, D., Feichtinger, P., Larkin, P., O’Connor, D., and Höner, O. (2018). Psychological talent predictors in youth soccer: a systematic review of the prognostic relevance of psychomotor, perceptual-cognitive and personality-related factors. PLOS ONE 13:e205337. doi: 10.1371/journal.pone.0 205337

Nortje, L., Dicks, M., Coopoo, Y., and Savelsbergh, G. J. P. (2014). Put your money where your mouth is: verbal self-reported tactical skills versus online tactical performance in soccer. Int. J. Sports Sci. Coach. 9, 321-334. doi: 10.1260/1747-9541.9.2.321

Owen, A. L., Twist, C., and Ford, P. (2004). Small-sided games: the physiological and technical effect of altering pitch size and player numbers. Insight 7, 50-53.

Pellegrini, A. D., Dupuis, D., and Smith, P. K. (2007). Play in evolution and development. Dev. Rev. 27, 261-276. doi: 10.1016/j.dr.2006.09.001

Pellegrini, A. D., and Smith, P. K. (1998). The development of play during childhood: forms and possible functions. Child Psychol. Psychiatry Rev. 3, 51-57. doi: 10.1017/S1360641798001476

Rampinini, E., Impellizzeri, F. M., Castagna, C., Abt, G., Chamari, K., Sassi, A., et al. (2007). Factors influencing physiological responses to small-sided soccer games. J. Sports Sci. 25, 659-666. doi: 10.1080/02640410600811858

Roca, A., Williams, A. M., and Ford, P. R. (2012). Developmental activities and the acquisition of superior anticipation and decision making in soccer players. J. Sports Sci. 30, 1643-1652. doi: 10.1080/02640414.2012.7 01761

Rodriguez-Ayllon, M., Derks, I. P. M., van den Dries, M. A., Esteban-Cornejo, I., Labrecque, J. A., Yang-Huang, J., et al. (2020). Associations of physical activity and screen time with white matter microstructure in children from the general population. Neuroimage 205:116258. doi: 10.1016/j.neuroimage.2019.1 16258

Savelsbergh, G. J. P., Haans, S. H. A., Kooijman, M. K., and van Kampen, P. M. (2010). A method to identify talent: visual search and locomotion behavior in young football players. Hum. Mov. Sci. 29, 764-776. doi: 10.1016/j.humov.2010.05.003

Savelsbergh, G. J. P., Van der Kamp, J., Williams, A. M., and Ward, P. (2005). Anticipation and visual search behaviour in expert soccer goalkeepers. Ergonomics 48, 1686-1697. doi: 10.1080/00140130500101346

Savelsbergh, G. J. P., Williams, A. M., van der Kamp, J., and Ward, P. (2002). Visual search, anticipation and expertise in soccer goalkeepers. J. Sports Sci. 20, 279-287. doi: 10.1080/026404102317284826

Savelsbergh, G. J. P., Onrust, M., Rouwenhorst, A., and Van Der Kamp, J. (2006). Visual search and locomotion behaviour in a four-to-four football tactical position game. Int. J. Sport Psychol. 37, 248-264.

Shim, J., Carlton, L. G., Chow, J. W., and Chae, W.-S. (2005). The use of anticipatory visual cues by highly skilled tennis players. J. Mot. Behav. 37, 164-175. doi: 10.3200/JMBR.37.2.164-175

Travassos, B., Araújo, D., Davids, K., O’Hara, K., Leitão, J., and Cortinhas, A. (2013). Expertise effects on decision-making in sport are constrained by requisite response behaviours - a meta-analysis. Psychol. Sport Exerc. 14, 211-219. doi: 10.1016/j.psychsport.2012.11.002

Tremblay, M. S., Barnes, J. D., González, S. A., Katzmarzyk, P. T., Onywera, V. O., Reilly, J. J., et al. (2016). Global matrix 2.0: report card grades on the physical activity of children and youth comparing 38 countries. J. Phys. Act. Health 13, S343-S366. doi: 10.1123/jpah.2016-0594

Tremblay, M. S., Gray, C. E., Akinroye, K., Harrington, D. M., Katzmarzyk, P. T., Lambert, E. V., et al. (2014). Physical activity of children: a global matrix of grades comparing 15 countries. J. Phys. Act. Health 11, S113-S125. doi: 10.1123/jpah.2014-0177

Vaeyens, R., Lenoir, M., Williams, A. M., and Philippaerts, R. M. (2007) Mechanisms underpinning successful decision making in skilled youth soccer players: an analysis of visual search behaviors. J. Mot. Behav. 39, 395-408. doi: 10.3200/JMBR.39.5.395-408

Vaeyens, R., Lenoir, M., Williams, A. M., and Philippaerts, R. M. (2008). Talent identification and development programmes in sport current models and future directions. Sports Med. 38, 703-14. doi: 10.2165/00007256-200838090-00001

Van Der Kamp, J., Rivas, F., Van Doorn, H., and Savelsbergh, G. (2008). Ventral and dorsal system contributions to visual anticipation in fast ball sports. Int. J. Sport Psychol. 39, 100-130.

Weissensteiner, J., Abernethy, B., Farrow, D., and Müller, S. (2008). The development of anticipation: a cross-sectional examination of the practice experiences contributing to skill in cricket batting. J. Sport Exerc. Psychol. 30, 663-684. doi: 10.1123/jsep.30.6.663

Williams, A. M., and Elliott, D. (1999). Anxiety, expertise, and visual search strategy in karate. J. Sport Exerc. Psychol. 21, 362-375. doi: 10.1123 /jsep.21.4.362

Williams, A. M., and Reilly, T. (2000). Talent identification and development in soccer. J. Sports Sci. 18, 657-667. doi: 10.1080/026404100501 20041

Woods, C. T., Joyce, C., and Robertson, S. (2016a). What are talent scouts actually identifying? Investigating the physical and technical skill match activity profiles of drafted and non-drafted U18 Australian footballers. J. Sci. Med. Sport 19, 419-423. doi: 10.1016/j.jsams.2015.04.013

Woods, C. T., Raynor, A. J., Bruce, L., and McDonald, Z. (2016b). Discriminating talent-identified junior Australian football players using a video decisionmaking task. J. Sports Sci. 34, 342-347. doi: 10.1080/02640414.2015.1 053512

Conflict of Interest: The authors declare that the research was conducted in the absence of any commercial or financial relationships that could be construed as a potential conflict of interest.

Copyright (c) 2021 de Joode, Tebbes and Savelsbergh. This is an open-access article distributed under the terms of the Creative Commons Attribution License (CC BY). The use, distribution or reproduction in other forums is permitted, provided the original author(s) and the copyright owner(s) are credited and that the original publication in this journal is cited, in accordance with accepted academic practice. No use, distribution or reproduction is permitted which does not comply with these terms. 


\section{APPENDIX}

\section{A. Set-Up for Footage for the GID Clips}

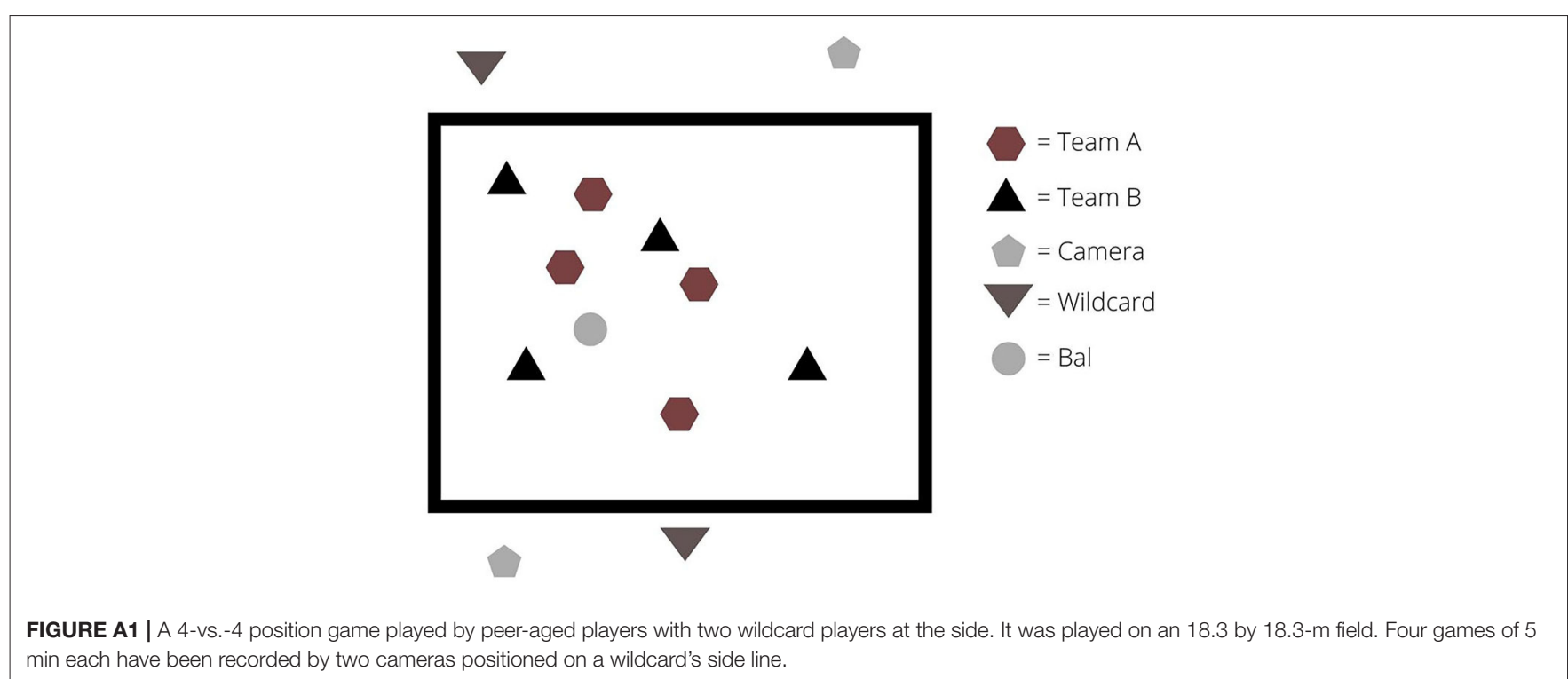

